UDC 336.225.613

JEL Classification: H2O, H71

DOI: $10.15587 / 2706-5448.2020 .218711$

\section{Zolkover A., Kovalenko D.}

\title{
EVOLUTION OF THEORIES OF SHADOW ECONOMY FORMATION
}

The object of research is the theory of formation of the shadow sector of the economy. The paper presents an evolutionary analysis of theories of the shadow economy emergence. It deals with the study of the main theories of the emergence of the informal sector of the economy and determines their features, preconditions of origin, and drivers. Based on the systematization of literary research of scholars, the following groups of theories have been identified: modernization theory, neoliberal theory, institutional theory, the theory of political economy. The analysis of the economic content of the concept of the shadow economy emergence has been used to identify the most influential drivers of the transition of economic entities into the «underground». In particular, the most influential factors include the level of centralization of power, the economic development of the country, the quality of the institutional environment, etc. The analysis of approaches to understanding the definition of the «shadow economy» revealed ambiguous interpretations of the concept of the shadow economy and a significant number of synonyms used in the study of the shadow economy. The Google Trends toolkit was used to prove the multivariate approaches to understanding the essence of this phenomenon. The most common interpretations include the shadow economy, the informal economy, the underground economy, the black economy, and the non-observed economy. The bibliometric analysis of scientific publications in journals indexed in Scopus and WoS databases for 2014-2020 yielded three main clusters, which combine papers that deal with the study of the theory of shadow economy. They are as follows: the shadow economy emerges mainly due to low rates of economic development of the country; the shadow economy emerges due to high unemployment; the growing share of the shadow sector of the economy is a consequence of ineffective government policies. The study concluded that the key task in the implementation of state policy aimed at combating the shadow economy should be coordination the state prevention measures with the most influential drivers of growth in the share of the shadow sector of the economy.

Keywords: shadow economy, theory of shadow economy emergence, bibliometric analysis, policy of unshadowing the economy, economic development.

\section{Introduction}

Trends in the development of the national economy of most countries across the world are characterized by unstable indicators of their economic and social development, imbalances in the economy, a deficit of budgetary funds, low efficiency of government measures, etc. One of the main problems in the functioning of the modern economy is the permanent growing volume of shadow financial transactions. Considering the significant influence of the shadow economy on various components of the country's development, an evolutionary analysis of the essence of the shadow economy and the prerequisites for its formation become of scientific and practical significance.

\section{The object of research and its technological audit}

The object of research is the theory of formation of the shadow sector of the economy. Given the high share of the shadow sector, the problem of developing and implementing measures aimed at bringing economic entities out of the shadow economy, introducing preventive measures aimed at preventing the participation of economic enti- ties in shadow operations is becoming especially urgent. A prerequisite for the effective implementation of these measures is taking into account the main drivers of the shadow economy, which strength and nature of influence are determined by the level of economic development of the country, the phase of the country's business cycle, etc. For this purpose, the article will analyze the main theories of the emergence of the shadow economy to identify the most influential catalysts for shadow operations. The phenomenon of the shadow economy will be investigated in this paper using the Google Trends search engine. This will allow forming a comprehensive understanding of the object of research, determining the peaks in the investigation of this issue, and the nature of their dependence on a time basis. The use of the VOSviewer v.1.6.10 data analysis package will allow for bibliographic mapping of the theories of shadow economy emergence, identifying key phrases that are most often associated with the object of research, and forming clusters of shadow economy emergence theories. The combination of Google Trends search engine and VOSviewer software will produce more reasonable results. Despite a significant number of publications that deal with this problem, some issues are insufficiently substantiated and understudied in modern 
scientific literature, which determines the relevance of further research.

\section{The aim and objectives of research}

The study aims to develop a theoretical framework for identifying the most influential drivers of the shadow economy in the context of the implementation of state policy to counter it.

Achieving this goal requires fulfilling the following scientific goals:

1. Systematizing the theories of the shadow economy emergence, determining their characteristic features to find the main areas for increasing the effectiveness of state policy of unshadowing the economy.

2. Bibliographic mapping of the citation of articles on the theory of the shadow economy emergence, their clustering according to the criterion of connection with other theories.

\section{Research of existing solutions of the problem}

The functioning of the shadow economy has been attracting the attention of scientists for a long time. The scientific school of the International Monetary Fund is quite powerful in the area of the research into the peculiarities of the shadow financial transactions. In particular, the authors of [1] identified the main determinants of growth in the share of the shadow economy and developed a scientific and methodological approach to assessing the level of the shadow economy. These studies can be continued by taking into account the most influential factors of the shadow economy emergence and their influence on the behavior of economic agents when building a policy to counter shadow operations. Experts from the Ministry of Economic Development and Trade of Ukraine publish an annual analytical report on general trends in the shadow economy in Ukraine [2], which presents the results of assessing the integral level of the shadow economy and the drivers that cause it. At the same time, this report is a review report and does not contain proposals for specific tools for unshadowing the economy. The team of the National Academy of Internal Affairs [3] has characterized the most effective mechanisms for combating shadow financial transactions, proposed promising tasks for the development of a system for countering the shadow economy. The authors of $[4,5]$ deepened the methodological foundations of improving the state policy of unshadowing the economy by taking into account the methods of fuzzy logic when determining the posterior probability of reaching a certain level of its effectiveness, developed strategies for unshadowing the economy depending on the nature of the individual components of the state economic policy.

The authors of $[6,7]$ studied the relationship of shadow transactions with the indicators of monetary policy. But the dependence of this influence on the level of economic development of the country remains.

The crisis of public confidence as a driver of growth in the volume of shadow financial transactions has been studied in scientific papers [8, 9]. However, the issues of systematization of directions and strength of influence of this indicator on the shadow sector of the economy remained unresolved.
In [10], the authors investigated the impact of the shadow sector of the economy on the amount of tax revenues in the country and substantiated the concept of tax gaps. At the same time, the authors did not pay attention to the justification of the relationship between tax rates and the level of shadowing.

However, the analyzed studies are fragmentary and sporadic, do not form a systemic basis for increasing the effectiveness of the state policy for unshadowing the economy in the context of macroeconomic instability of the country.

In general, the overwhelming majority of scientific works devoted to the study of the evolution of scientific views of the concept of the shadow economy consider these issues separately from each other and do not provide for the systematization of scientific schools that investigated these aspects.

\section{Methods of research}

During the research, general scientific and special methods were used, in particular:

- analysis and synthesis - for the analysis and generalization of the main theories of the formation of the shadow economy, determination of the frequency of queries of users of the Google Trends search engine in the context of definitions of the shadow economy; - graphical method - for network visualization of citation of articles on the theory of the shadow economy indexed in the scientometric WoS database using the VOSviewer toolkit;

- statistical method - for the analysis of quantitative parameters of the study of the theory of the shadow economy.

\section{Research results}

The shadow economy emergence is a complex research concept that requires the use of a range of methods of econometric and statistical analysis.

The phenomenon of the «informal sector» was first introduced by the British sociologist and anthropologist Keith Hart back in the early 1970s. Studying the economies of Kenya and Ghana [11], the scientist emphasized the high level of informal employment and the paradoxically low level of the official economy in these two countries.

In the 1980s, the scope of shadow economy research expanded and included the study of shadow activities not only in countries with a low level of economic development but also in countries with developed economies. Empirical and theoretical studies of those times showed that the shadow economy is a universal phenomenon that exists in all countries.

Thus, the shadow economy began to be considered not only as a universal characteristic of the economy but as part of the daily life of society. Systematization of scientific expertise in the field of shadow economy emergence shows that over the past two decades, these issues have constantly been the subject of scientific interest. This is evidenced by a growing number of theoretically and empirically focused studies on various aspects of the shadow economy $[12,13]$. These issues are constantly the focus of the attention of representatives of the International Labour Organization (ILO), the World Bank, the International Monetary Fund (IMF), and the Organization for Economic Cooperation and Development (OECD). 
Today the scientific literature contains a significant variety of approaches to the interpretation of the essence, prerequisites for the formation and consequences of the existence of the shadow economy. Thus, the most common include: underground economy, informal economy, shadow economy, black economy, hidden economy, illegal economy, unregistered economy, gray economy, illegal economy, etc. A bibliometric mapping of scientific publications in journals indexed in the Scopus and WoS databases for 2014-2020 was carried out to analyze the frequency of research on theories of the shadow economy emergence. During the analyzed period, the frequency of research on this issue remained unchanged and ranged from $20-30$ publications in both analyzed databases. Graphical interpretation of the results obtained using the VOSviewer toolkit made it possible to identify the main clusters that combine works that deal with the study of the theory of shadow economy emergence (Fig. 1).

The first largest cluster (green) combines publications containing the following keywords: informal sector, informal economy, corruption, tax morals, growth, tax evasion. Thus, within this cluster, the emergence of the shadow economy is mainly explained by the indicators of the country's economic development. The second largest cluster (blue) includes the following keywords: unemployment, markets, participation, employment, etc. The last cluster (red) contains the following keywords: institutional theory, government, political economy, politics, power, etc. Thus, this cluster combines the key characteristics of the institutional theory of the emergence of the shadow economy.
To obtain reliable results on the study of shadow economy theories, we will analyze the search trends of 5 main terms that most often explain the phenomenon of the shadow economy using the Google Trends toolkit for the period from January 1, 2004 to June 15, 2020. As indicated in Fig. 2, the interest of scientists in the subject under study is at a stable level. The phrase «black economy» is at the top of the search. Its search frequency reaches 100. The phrase «non-observed economy» has the lowest search frequency (less than 10). Phrases «shadow economy» (6-11), «informal economy» (13-20), «underground economy» $(7-20)$. As a rule, the peak of discussion of the studied aspects falls at the end of the year (November-December). At the same time, in recent years, there has been a gradual increase in the frequency of research on the term «informal economy» (2 times).

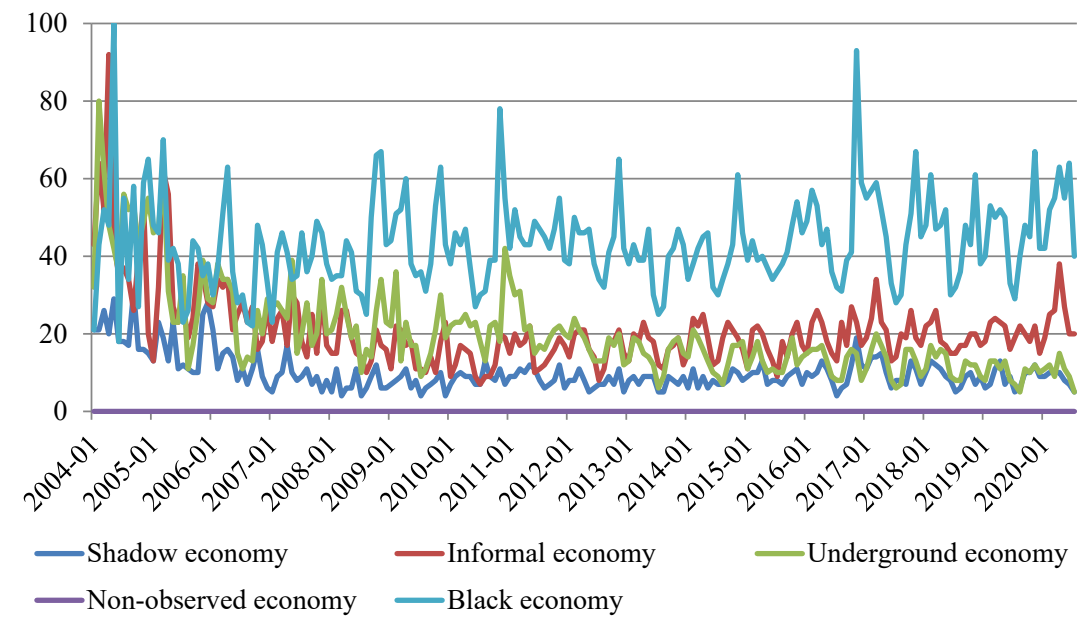

Fig. 2. Dynamics of changes in the frequency of search in the context of definitions of the shadow economy in the world according to Google Trends for the period from January 1, 2004 to June 15, 2020 (constructed by the authors based on the data from the Google Trends toolkit)

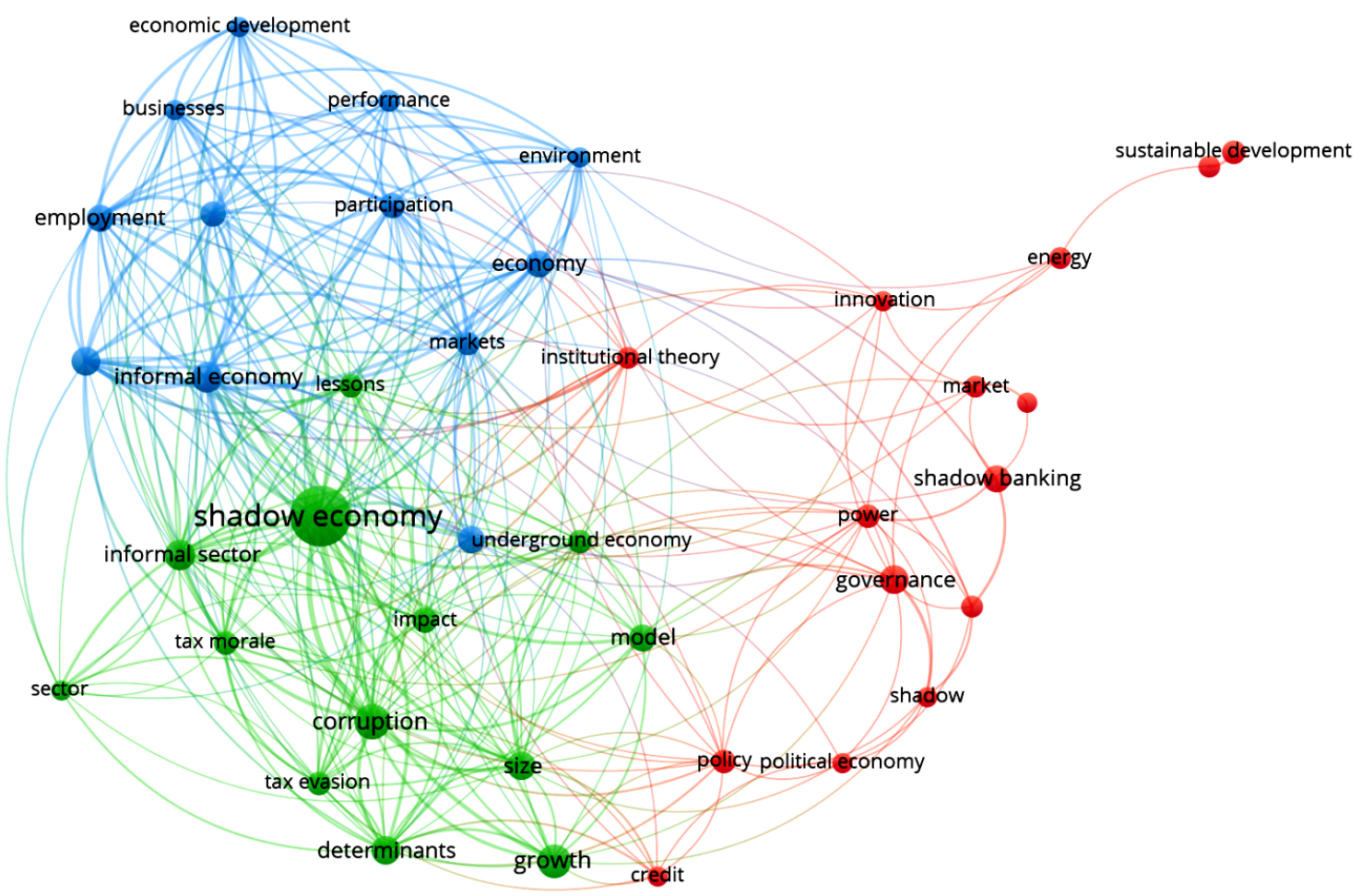

Fig. 1. Network visualization of citation of articles on theories of the shadow economy emergence (constructed by the authors based on the data from the WoS scientometric database and the VOSviewer software) 
In general, based on the results of the analysis, it can be concluded that although the term shadow economy has been used in the scientific literature for more than 35 years, this phrase has not been displayed at the top of the search results given by the system since May 2005. Thus, the results of the analysis confirmed the conclusions about the ambiguous interpretation of the concept of the shadow economy and the presence of a significant number of synonyms used in the study of the shadow economy.

The scientific literature has a significant variety of theories of the formation of the shadow economy, in particular:

1. The modernization theory, which connects the phenomenon of the shadow economy with the low level of economic development of the country and the lack of modern methods of management and modernization in the structure of public administration [14]. Representatives of this theory argue that the modern official sector is broad and growing, while they see the informal sector as gradually disappearing. Thus, informal entrepreneurs are considered as a remnant of the pre-modern production system, and their presence in the country is evidence of the «underdevelopment» of its economy and the lack of modernization of its management system.

2. The neoliberal theory states that the level of shadowing is higher in countries with a high degree of centralization of power. Excessive government intervention in the free market forces entrepreneurs to make decisions about moving to the informal sector, which is characterized by shorter duration, costs, and efforts to implement bureaucratic procedures. Thus, for neoliberal theory, shadow activity is a rational economic solution for economic entities that face a burdensome regulatory environment. Shadowing is the result of excessive regulation, high taxes, and excessive government intervention.

3. The theory of political economy, in contrast to the neoliberal theory, determines the main prerequisite for the emergence of the shadow economy by a high level of decentralization of power, non-interference of the state in almost all aspects of the functioning of humanity. Both in the economy and in the system of social protection and social transfers.

4. The institutional theory considers the emergence of the shadow economy to be a result of an imbalance between the requirements of laws and rules of formal government institutions and the norms and beliefs of informal institutions. A feature of all the aforementioned theories is that they do not take into account the free will of the individual and do not explain why some business entities move to the shadow sector of the economy, while others do not. At the same time, institutional theory views state institutions as certain rules of the game that regulate and determine the behavior of the individual. Every society has both formal institutions (i. e. laws and regulations), which are the legal rules for doing business, and informal institutions, which are socially shared norms, values, and beliefs about what is right and acceptable in society. Thus, the subjects of the official sector of the economy try to comply with official institutional prescriptions (i. e. laws and regulations), while the subjects of the shadow economy operate outside the official rules of the game, but within the norms, values, and beliefs of informal institutions. Criminal entrepreneurship, in turn, goes beyond both formal and informal rules of the game. One of the key categories of institutional theory is the concept of «transaction costs», which explains the mechanisms of the emergence and implementation of informal practices in everyday business activities. The institutional area was further developed in emerging economies and created a conceptual framework for the development of methodologies for the empirical study of the shadow economy.

Despite considerable research into these issues, so far none of these theories has found its full justification, periodically questioning their reliability. Based on the analysis of bilateral correlations between the volumes of the shadow sector and the determinants of the economic countries of the European Union, Central and Eastern Europe, Latin America, and developing countries, scientists concluded the reliability of the modernization theory, the theory of political economy and institutional theory, and the low level of reliability of the neoliberal theory.

\section{SWOT analysis of research results}

Strengths. Strengths include the systematization of theories of the shadow economy emergence and network visualization of citing articles on the theory of the shadow economy emergence.

Weaknesses. The study showed a significant variety of approaches to the interpretation of the prerequisites for the implementation of shadow operations by economic entities, which complicates the procedures for the development and implementation of measures aimed at preventing the emergence of the shadow economy, taking into account the set of drivers that have the greatest impact on the level of the shadow economy.

Opportunities. Prospects for further research are the construction of an econometric model for forecasting the level of the shadow economy, depending on the nature of changes in the drivers of influence in dynamics.

Threats. One of the threats to the implementation of measures to unshadow the national economy is the significant variability of the external and internal environment of business functioning, which leads to a change in the set of factors that determine the level of the shadow economy.

\section{Conclusions}

1. The work involved the systematization of theories of the emergence of the shadow economy, by highlighting the modernization theory, neoliberal theory, institutional theory, and the theory of political economy. Based on the definition of their characteristic features, the main drivers of the emergence of the shadow economy have been substantiated, among which the following are highlighted: the level of centralization of power, the country's economic development, the quality of the institutional environment, etc.

2. A bibliographic mapping of the citation of articles on the theory of the emergence of the shadow economy was carried out, which made it possible to determine three clusters of the connection of this concept with other theories. The frequency of research of the concept of the shadow economy according to temporal and substantive criteria was determined based on the use of the Google Trends toolkit.

\section{References}

1. Williams, C., Schneider, F. (2016). Measuring the Global Shadow Economy: The Prevalence of Informal Work and Labour Hardcover. Measuring the Global Shadow Economy: The Prevalence of Informal Work and Labour, 247. 
2. Zahalni tendentsii tinovoi ekonomiky v Ukraini u 2019 rotsi (2019). Department ekonomichnoi stratehii ta makroekonomichnoho rozoytku $i$ torhivli Ukrainy. Available at: https://ucap.io/ wp-content/uploads/2020/06/1 shadow 2019.pdf

3. Cherniavskyi, S. S., Nekrasov, V. A., Tytko, A. V. (Red.) (2017) Tinova ekonomika o Ukraini: stan, tendentsii, shliakhy podolannia. Kyiv: Natsionalna akademiia vnutrishnikh sprav, 152.

4. Berdiev, A. N., Saunoris, J. W. (2016). Financial development and the shadow economy: A panel VAR analysis. Economic Modelling, 57, 197-207. doi: http://doi.org/10.1016/j.econmod. 2016.03.028

5. Mazhar, U., Méon, P.-G. (2017). Taxing the unobservable: The impact of the shadow economy on inflation and taxation. World Development, 90, 89-103. doi: http://doi.org/10.1016/j.worlddev. 2016.08.019

6. Chen, K., Ren, J., Zha, T. (2018). The Nexus of Monetary Policy and Shadow Banking in China. American Economic Review, 108 (12), 3891-3936. doi: http://doi.org/10.1257/aer.20170133

7. Foster, C., Frieden, J. (2017). Crisis of trust: Socio-economic determinants of Europeans' confidence in government. European Union Politics, 18 (4), 511-535. doi: http://doi.org/10.1177/ 1465116517723499

8. Lins, K. V., Servaes, H., Tamayo, A. (2017). Social Capital, Trust, and Firm Performance: The Value of Corporate Social Responsibility during the Financial Crisis. The Journal of Finance, 72 (4), 1785-1824. doi: http://doi.org/10.1111/jofi.12505

9. Moreira, A., Savov, A. (2017). The Macroeconomics of Shadow Banking. The Journal of Finance, 72 (6), 2381-2432. doi: http:// doi.org/10.1111/jofi.12540
10. Tiutiunyk, I., Kobushko, I., Ivaniy, O., Flaumer, A. (2019). Innovations in the management of tax gaps in the economy: foreign economic component. Marketing and Management of Innovations, 3, 112-125. doi: http://doi.org/10.21272/mmi.2019.3-09

11. Hart, K. (1973). Informal Income Opportunities and Urban Employment in Ghana. The Journal of Modern African Studies, 11 (1), 61-89. doi: http://doi.org/10.1017/s0022278x00008089

12. Tiutiunyk, I. V., Humenna, Yu. H. (2018). Illicit financial flows of economic subjects: value aspect. Prychornomorski ekonomichni studii, 33, 208-212.

13. Osipov, G. V., Glotov, V. I., Karepova, S. G. (2018). Population in the shadow market: petty corruption and unpaid taxes. Entrepreneurship and Sustainability Issues, 6 (2), 692-710. doi: http:// doi.org/10.9770/jesi.2018.6.2(16)

14. Medina, L., Schneider, F. (2018). Shadow Economies Around the World: What Did We Learn Over the Last 20 Years? IMF Working Papers, 18 (17), 1. doi: http://doi.org/10.5089/9781484338636.001

Zolkover Andrii, PhD, Associate Professor, Department of Economics and Services, Kyiv National University of Technologies and Design, Kyiv, Ukraine, e-mail: zaaaaa@ukr.net, ORCID: http://orcid.org/ 0000-0002-8176-1850

Kovalenko Dmytro, PhD, Associate Professor, Department of Finance and Financial and Economic Security, Kyiv National University of Technologies and Design, Kyiv,Ukraine,e-mail:kdi75@ukr.net, ORCID: http://orcid.org/0000-0002-0853-0546 